\title{
PUBLICACIÓN EN TIEMPO DE CUARENTENA: EDICIÓN DE UNA REVISTA EN EPOCAS DE CAMBIO E INCERTIDUMBRE
}

\section{Publication in quarantine time: edition of a magazine in times of change and uncertainty}

\section{Wileidys Artigas*}

https://orcid.org/0000-0001-6169-5297

Como citar: Artigas, Wileidys. (2020). Publicación en tiempo de cuarentena: ciencia en épocas de cambio e incertidumbre. Telos: revista de Estudios Interdisciplinarios en Ciencias Sociales, 22 (2), Venezuela. (Pp.254-256).

DOI: www.doi.org/10.36390/telos222.01

El año 2020 inicio bajo algunos parámetros distintos, pero nadie podía imaginarse que tan distinto iba a empezar a tornarse a partir de finales de febrero. Lo que se conocía como cambio e incertidumbre de la época moderna se tornó en otros significados, y al parecer seguirá modificando la concepción que se tiene acerca de dichos conceptos. De ahora en adelante los procesos que comúnmente se estaba acostumbrado a implementar muy posiblemente sean distintos y tengan otras formas de aplicación más ligadas a herramientas tecnológicas.

El lugar de trabajo dejo de ser una oficina y se convirtió en todo aquel lugar en el cual se pueda tener una conexión para llevar a cabo los procesos que se deben implementar. Quizás un espacio físico es sustituido por un espacio virtual y las personas empiecen a valorar la presencia que antes era muy común. Definitivamente ya nada será igual.

Esta publicación es un poco distinta de las anteriores, porque si bien es cierto que algunos de los documentos ya habían sido aceptados antes de la implementación de la cuarentena, algunos otros han sido corregidos en una época distinta y bajo unos procesos personales distintos, quizás los autores tuvieron que comunicarse virtualmente para culminarlo o quizás comenzaron a usar herramientas para reunirse virtualmente. Hay algo que si debemos

\footnotetext{
* Editora de la Revista. Doctora en Ciencias Sociales, mención Gerencia. Profesora e investigadora de la Facultad de Ciencias Económicas y Sociales de la Universidad del Zulia. Asesora en el área de Revistas Científicas de la Universidade Óscar Ribas de Angola. Correo electrónico: wileidys@hotmail.com; wileidys.artigas@urbe.edu.ve
} 
agradecer y es que toda dificultad nos da una gran oportunidad de aprendizaje, y eso es lo que estamos enfrentando, una época de gran valía en cuanto a aprendizaje.

Este segundo numero de 2020 refleja esa disciplina y constancia de los autores en el cumplimiento de su labor, quizás bajo circunstancias no optimas, pero con gran capacidad de respuesta ante lo solicitado, se presentan artículos y un documento de traducción, enlistados con su respectivo país de origen a continuación:

- Orlando Márquez Caro, Ricardo Cosio Borda, Fernando Márquez Caro y Manuel Manrique Nugent, Perú, Competitividad de la Tara Peruana en el comercio internacional, periodo 20102018; un tema sobre competitividad de productos nacionales en el ámbito internacional.

- Mayerly Parra Fuenmayor y María Alejandra Ferrer, Venezuela, Gestión de Tesorería en Hospitales privados del estado Zulia, Venezuela, en donde se destaca el proceso financiero dentro de entidades de salud privadas.

- Milagros Rodríguez y Mireya Mirabal Rodríguez, Venezuela, Ecosofía-Antropoética: Una recivilización de la humanidad, en el que se destaca el cambio de pensamiento, muy vigente para la época actual.

- Leonardo Favio Osorio, Venezuela, Los mitos latinoamericanos: vigencia de la obra "del buen salvaje al buen revolucionario"; en donde se analiza un texto que trata sobre temas importantes para los procesos políticos enfrentados por los latinoamericanos.

- Oshiel Martínez Chapa, México, La inflación en la perspectiva de la escuela austriaca, en donde se analiza la inflación desde la perspectiva de una de las escuelas de pensamiento que la estudian, de manera que se puede observar la diferencia con otras escuelas.

- Fernando Torres Granadillo y Morela Pereira Burgos, Venezuela, Estrategias de sostenibilidad en ciudades fronterizas afectadas por la migración. El caso de la ciudad de Maracaibo, en el que tratan este tema tan vigente en función de los movimientos actuales de los migrantes como consecuencia de las medidas de cuarentena.

- Tania Silverio Pérez, Wang Ye y Caridad Abreu López, Cuba y Angola, La pronunciación de los profesores de español como lengua extranjera y segunda lengua: la realidad del aula, en el que se muestra desde la lingüística estos procesos en la enseñanza del idioma.

- Nely Monterrosa, Colombia, Competencias ciudadanas: ejes presentes en el sector estudiantil colombiano; en el cual se trata este tema de importancia para ser educado en las universidades.

- Eduardo Sandoval Forero y José Capera Figueroa, México, Dilemmas and advances in postconflict in Colombia: a look from the subaltern perspective of peace (s) in the territories, estudio en ingles que trata sobre el conflicto en Colombia.

- Jorge Ormaza Andrade, mercedes Neira Neira, Lesi Giler Escandón y Jorge Quevedo Vázquez, Ecuador, Maquina Bio-Recicladora de plástico PET: Un emprendimiento viable. Caso Azogues-Ecuador, en donde se presenta el estudio de factibilidad para la implementación de dicho emprendimiento.

- Miguel Olivo Pérez y Juan Abud Jaso, México, Estudio comparativo de la ética ante lo nuevo en la investigación acción y el maoísmo, en donde destaca la importancia de la ética ante lo nuevo. 
- Abrahán Neri Ayala; Santiago Ramos y Yovera y Felix Caro Soto, Perú, Herramientas Google en el aprendizaje de matemática financiera en los estudiantes universitarios, en donde demostraron lo que mejora el aprendizaje con el uso de herramientas de Google.

- Alicia Pineda, La argumentación como resolución de problemas en el discurso neocorporativista de políticas venezolanas (1989-1994). Análisis crítico, Venezuela, en donde presenta el tema de la argumentación como soporte discursivo.

Finalizando con dos documentos, una traducción y un documento:

- Traducción: Ernesto Laclau y los estudios críticos de los medios: marxismo, capitalismo y critica de Jannick Schou, por Adrián Montero de Costa Rica.

Como puede observarse, la disciplina de los autores en la conclusión de sus trabajos ha hecho que este número no sea fallido, tomando en cuenta las medidas actuales de cuarentena y resguardo de la población. Desde distintos países se ha logrado el cometido de la publicación en diversas áreas del conocimiento.

Esperemos que pronto regresemos a la normalidad o que creemos una nueva normalidad que nos permita seguir avanzando en los procesos de indización iniciados este año y en una mayor internacionalización de la revista, para el último número del 2020 se llevará a cabo una colaboración de edición internacional con el profesor Robinson Salazar de México, quien ha logrado convocar diversos autores latinoamericanos para hablar sobre "América Latina en la encrucijada del siglo XXl", el cual esperamos con mucho agrado, pues convoca intelectuales de América Latina que fortalecerán el reconocimiento e intercambio de la revista; así mismo, bien recibidos serán todos aquellos artículos que generen nuevo conocimiento relacionado con los cambios en las ciencias sociales luego del Covid-19. 